EMS Annual Meeting Abstracts

Vol. 18, EMS2021-34, 2021

https://doi.org/10.5194/ems2021-34

EMS Annual Meeting 2021

(C) Author(s) 2021. This work is distributed under

the Creative Commons Attribution 4.0 License.

\title{
From climate information to climate services: the need for a Belgian climate service centre
}

\author{
Rozemien De Troch $^{1}$ and Piet Termonia ${ }^{1,2}$ \\ ${ }^{1}$ Royal Meteorological Institute, Brussels, Belgium (rozemien.detroch@meteo.be) \\ ${ }^{2}$ Ghent University (UGent), Department of Physics and Astronomy, Ghent, Belgium
}

The Belgian expertise with respect to climate research is very fragmented and led by both federal (like the Royal Meteorological Institute of Belgium, hereafter RMI) as well as regional scientific research institutions and universities. Furthermore, both in societal, research as well as policy context there is an increasing need for detailed, quantitative, reliable and consistent climate information and services, in particular linked to the expected climate changes and its impacts in different sectors (e.g. water, agriculture, energy, health, transport).

To make all this scientific expertise and climate information available in a coordinated and, above all, user-friendly way, a Belgian climate centre or a one-stop shop for climate research and services would fully address the needs. With its long-standing scientific expertise and service provision, RMI plays a crucial role in fulfilling this growing need for climate information and services.

Hence, RMI has elaborated a proposal on the creation of a Belgian climate centre. For the creation of such centre it is preferable to use existing collaborations from previous or ongoing research and service-provision activities in Belgium, requiring a structural cooperation in which each members' expertise can be fully deployed. In the context of a previous research project, a large consortium of Belgian research institutions active in regional climate modelling, calculated for the first time a consistent set of high-resolution climate projections and sectoral impacts for Belgium. Nevertheless, it should be emphasized that the number of models used was far too limited to develop reliable information of the future climate. Moreover, this was a one-time project and there is currently an urgent need to update the climate projections to meet the new scientific requirements of the IPCC's new sixth Assessment Report.

One of the activities of the centre would thus be the coordination of the climate research based on scientific research projects. Furthermore, in order to ensure the continuous development and provision of climate services based on this objective and scientifically based expertise coming from Belgian climate scientists, the climate centre would carry out two main core tasks: (i) the production and storage of climate information and (ii) the support for the development of climate services.

The financing and implementation of a Belgian climate centre, would provide a structural framework for climate research and services, establishing partnerships with the various regions and communities, at both policy and research levels. In this way, RMI, as national meteorological institute and at the start of the climate services value chain, can guarantee a continuous scientific expertise and respond to the major needs for climate information and services at national and international level. 
